\title{
VI Encuentro Internacional de Compositores en Chile: Mujeres Compositoras
}

Entre el domingo 3 y el viernes 8 de agosto de 2014 se desarrolló el VI Encuentro Internacional de Compositores en Chile: Mujeres Compositoras, en el Instituto de Música de la Pontificia Universidad Católica.

El domingo 3 de agosto en el Centro Gabriela Mistral (GAM) se dio inicio a esta sexta bienal dedicada a la creación musical actual que se realiza desde el 2004 en el Instituto de Música de la Pontificia Universidad Católica (IMUC) bajo la coordinación general del compositor Pablo Aranda, junto al compositor Andrés Núñez y quien escribe estas líneas.

Por primera vez este encuentro estuvo dedicado únicamente a difundir y promover el trabajo de destacadas mujeres compositoras. Durante una semana participaron en las dependencias del Instituto de Música de la Universidad Católica (IMUC) las compositoras Brigitta Muntendorf (Alemania), Florentine Mulsant (Francia), Natalia Solomonoff (Argentina), Cecilia Cordero (Chile) y la chelista y compositora Émilie Girard-Charest (Canadá). Se vincularon las temáticas de creación, música y género, lo que tuvo una excelente acogida tanto de estudiantes como de los pares músicos y del público en general.

Las compositoras invitadas realizaron talleres de composición y conferencias. Además participaron en conciertos, en una mesa redonda, en audiciones plenarias y en talleres-lectura entre otras actividades, las que convocaron no solo a participantes de Santiago, sino que de otras regiones de nuestro país y del extranjero. En esta edición se contó con la visita de dos estudiantes del Ecuador.

Junto a las compositoras, también fueron invitados al VI Encuentro el pianista Daniel Añez (Colombia-Canadá), la violinista Geneviève Liboiron (Canadá), el clarinetista Eduardo Spinelli (Argentina) y la musicóloga Gesine Schröder (Austria-Alemania), quien a la fecha ha publicado dos reseñas sobre esta bienal en revistas especializadas de música en Austria²

Para los dos conciertos del VI Encuentro el equipo organizador programó solo obras de compositoras, las que en nuestro país tienen pocos espacios en un medio dominado ampliamente por hombres. En los conciertos realizados los días domingo 3 y viernes 8 de agosto se interpretaron junto a obras de cada una de las invitadas extranjeras composiciones de las chilenas Leni Alexander y Cecilia Cordero. Esta última fue invitada como representante de nuestro país al VI Encuentro y se estrenó su obra Adónde voy (2014), compuesta especialmente para esta oportunidad. Asimismo se presentaron piezas de Hilda Paredes (México), Graciela Paraskevaídis (Argentina/Uruguay), Candelaria Zamar (Argentina), Olga Neuwirth (Austria), Graciane Finzi (Francia), Joane Hétu (Canadá), Analía Llugdar (Argentina/Canadá) y de Kaija Saariaho (Finlandia), este último un notable estreno en Chile realizado por Karina Fisher.

Ambos conciertos se efectuaron ante una sala llena. Numerosos asistentes no pudieron ingresar debido al entusiasmo del público que retiró con anterioridad la totalidad de entradas. Entre los intérpretes que dieron vida a los conciertos estuvieron los invitados extranjeros de Canadá y Argentina. De Chile participaron el Cuarteto Surkos y el Taller de Música Contemporánea dirigido por Pablo Aranda además de intérpretes invitados.

El concierto inaugural fue doblemente formativo. Incluyó la muestra del seminario La Música en Juego, un proyecto conjunto entre el Instituto Francés y el Instituto Goethe realizado entre el 28 de julio y el 1 de agosto, el que fue financiado por el fondo franco-alemán Elysée de Fomento a la Cultura. En dicho seminario, organizado por el mismo equipo que el Encuentro y dedicado igualmente a las mujeres compositoras, las invitadas Graciane Finzi (Francia) y Brigitta Muntendorf (Alemania) trabajaron durante una semana con estudiantes de la Universidad Metropolitana de Ciencias de la Educación y del Instituto de Música de la Universidad Catyólica (IMUC), respectivamente. Alcanzó una muy buena participación. Sus resultados fueron presentados por los estudiantes con las obras Personal Data de Maximilian Marcoll y Giochi de Graciane Finzi.

Las conferencias de las invitadas se refirieron a variadas temáticas. Brigitta Muntendorf habló acerca de "Composición multimedial y teatro musical experimental"; Natalia Solomonoff se refirió a "Músicas a contraluz. Reflexiones en torno a la creación musical”; Florentine Mulsant dictó la charla "El apego a las formas antiguas en mi música"; Émilie Girard-Charest presentó una conferencia-concierto

${ }^{2}$ Ver las revistas especializadas Österreichische Musikzeitschrift (ÖMZ, 5/2014) y Terz Magazin (http:/ / terz.cc/magazin.php?z=1\&id=419), ambas de Viena, Austria. 
sobre sus "Partituras verbales", y el pianista Daniel Áñez mostró su investigación "La no discursividad. En torno a la obra de Graciela Paraskevaídis".

La musicóloga Gesine Schröder abrió la penúltima jornada, dedicada a reflexionar sobre el tema de este VI Encuentro, con su conferencia "Composición, música y género", la que fue seguida de una mesa redonda. Esta resultó especialmente interesante por el cruce de temáticas entre la creación musical y asuntos particulares de problemáticas de género, lo que generó un fluido diálogo entre las invitadas y los estudiantes. A esta actividad fueron invitadas las compositoras nacionales Valeria Valle y Fernanda Carrasco, quienes pudieron mostrar y compartir su proyecto Resonancia Femenina que desarrollan en la Universidad Católica de Valparaíso.

Esta sexta versión del Encuentro se realizó gracias al auspicio del Consejo Nacional de la Cultura y las Artes (CNCA) por medio del Fondo de Fomento de la Música Nacional, del Goethe Institut, del Instituto Francés, el Fondo Elysée de Fomento a la Cultura, el Instituto de Música de la Universidad Católica, las Offices Jeunesse de Québec, la Universität für Musik und Darstellende Kunst de Viena y la Sociedad Chilena del Derecho de Autor (SCD). Además se contó con la colaboración del Departamento de Música y Sonología de la Universidad de Chile, el GAM y la Radio Beethoven. Gracias a estos apoyos se logró además que las actividades fueran gratuitas para todos los asistentes, lo que es ya habitual en esta bienal.

A pesar que en momentos previos a la realización del VI Encuentro pudieron haber surgido dudas sobre la acogida que tendría una temática cruzada por problemáticas de género, una idea que venía gestándose desde hace varias ediciones, el resultado objetivo fue de lo más alentador. Cabe destacar que en cinco de los seis Encuentros se ha contado con invitadas mujeres, las que siempre han sido muy bien recibidas en tanto compositoras. Al respecto, surge la pregunta ¿por qué podrían no haberlo sido? Resulta complejo que exista todavía la necesidad de generar y abrir instancias como estas de forma tan impuesta o arbitraria. Sin embargo, las conversaciones mantenidas, las preguntas y reflexiones compartidas, nos llevan a creer que sigue siendo necesario e importante apoyar a que la creación femenina tenga mayor espacio en nuestro campo musical, el que tradicionalmente ha estado cerrado a ellas, a pesar de contar con destacadas mujeres en nuestra historia musical.

Fernanda Ortega Departamento de Música, Universidad Metropolitana de Ciencias de la Educación, Chile lfortega@uc.cl 